ORIGINAL ARTICLE

\title{
Time To Pregnancy and occupational lead exposure
}

\author{
M Joffe, L Bisanti, P Apostoli, P Kiss, A Dale, N Roeleveld, M-L Lindbohm, M Sallmén, \\ M Vanhoorne, J P Bonde, Asclepios
}

Occup Environ Med 2003;60:752-758

See end of article for
authors' affiliations
.......................
Correspondence to:
Dr M Joffe, Imperial
College Faculty of
Medicine, Department of
Epidemiology \& Public
Health, St Mary's
Campus, Norfolk Place,
London W2 1PG, UK;
m.joffe@imperial.ac.uk
Accepted
7 November 2002

See end of article for authors' affiliations

Correspondence to: DrM Joffe, Imperia College Faculty of Medicine, Department of Epidemiology \& Public Health, St Mary's Campus, Norfolk Place, London W2 1PG, UK;

7 November 2002

\begin{abstract}
Background: Lead exposure is known to be harmful to the male reproductive system, including impairment of fertility. However, it is unclear whether currently existing low levels of exposure have this effect.

Aims: To study retrospectively current workers in lead using industries (battery manufacture, smelting, etc), and in non-lead using control industries, in four European countries, with Time To Pregnancy as the outcome variable, as part of the EU funded Asclepios Project.

Methods: Exposure assessment was mainly by blood lead values, which were available from the late 1970s, supplemented by imputed values where necessary. Three exposure models were studied: (1) short term (recent) exposure; (2) total duration of work in a lead using industry; and (3) cumulative exposure. A Cox proportional hazards model with discrete ties was used for the statistical analysis, with covariates for both partners.

Results: A total of 1104 subjects took part, of whom 638 were occupationally exposed to lead at the relevant time. Blood lead levels were mainly less than $50 \mu \mathrm{g} / \mathrm{dl}$. No consistent association of Time To Pregnancy with lead exposure was found in any of the exposure models, although reduced fertility was observed in one category each in models (2) and (3).

Conclusions: This basically negative result is unlikely to be due to the misclassification of key variables, to insufficient statistical power, or to bias, for example, response bias. If any impairment of male reproductive function exists at the levels of occupational lead exposure now current, it does not appear to reduce biological fertility.
\end{abstract}

ead exposure has long been known to be harmful to male fertility. ${ }^{1-16}$ Endpoints have included impaired semen quality, hormonal imbalance, and reduced fertility. Experimental research in rodents supports the epidemiological evidence on humans, albeit with some discrepancies that remain to be resolved. ${ }^{1}$ The mechanism of action of lead on the male reproductive system remains unclear. It may include a direct effect on the developing spermatozoa, disruption of the endocrine regulation of spermatogenesis, or both. ${ }^{1}$

However, exposure levels have decreased, blood lead levels above $50-60 \mu \mathrm{g} / \mathrm{dl}$ being unusual among lead workers nowadays, and it is unclear whether there is any adverse effect on male reproductive function at current occupational levels. In order to document the possible effects of current exposures, we undertook an international study of men in lead exposed occupations as part of the Asclepios Project, a study of occupational factors in male reproductive health, funded by the European Commission.

A report from the Asclepios Project has already been published on the association of lead exposure and semen quality ${ }^{17}$; sperm concentration was found to be reduced among men who had a blood lead concentration above a threshold of $44 \mu \mathrm{g} / \mathrm{dl}$.

This paper focuses on biological fertility, measured using Time To Pregnancy (TTP), the number of months of unprotected intercourse that elapse before conception occurs. This is a sensitive indicator of the biological fertility of a couple, and can be ascertained using a short questionnaire section that is acceptable to survey participants. ${ }^{18}$ There is currently some limited evidence that fertility may be decreased among men occupationally exposed even to low levels of lead..$^{12}$ A preliminary analysis has already been published, confined to short term effects, based on the early data to be collected, ${ }^{19}$ and a country specific report has also been published separately. ${ }^{3}$
Validity studies have shown that recall of TTP is accurate at the group level, ${ }^{20-23}$ even with duration of recall up to at least 20 years. ${ }^{23}$ Male respondents are able to answer questions on TTP, and the resulting data give the same TTP distributions ${ }^{24}$ and analytical results ${ }^{25}$ as information derived from women drawn from the same population.

\section{METHODS}

The design was a cross sectional survey, but with retrospective assessment of exposures and outcomes over respondents' reproductive histories, which approximates a retrospective cohort study, albeit based on current workers only. Data collection took place in four European countries. We approached companies whose employees are exposed to lead, and non-lead using companies as a control group, with a view to participation in the research; 28 companies agree to take part (for details, see table 1).

Data collection took place in 1997-98 (except for Finland: 1995-96). Men were eligible for the study if they had ever been married (or living as married). The Asclepios Project questionnaire ${ }^{18}$ was developed for the purpose of the study. The method of data collection varied according to local conditions, and included telephone and face-to-face interviews, postal questionnaires, and consultations carried out by the factory medical service. We attempted to identify noneligible subjects among the non-respondents, using a one page questionnaire.

TTP was measured as the reply to the question, "How long did it take your wife/partner to get pregnant?", preceded by filter questions on contraceptive behaviour. The Asclepios questionnaire focuses on the most recent birth (youngest child) for detailed questioning, as it is the most likely to have occurred during employment in the selected industry. The questionnaire was originally written in English and translated as necessary. Only pregnancies that resulted in births 
Main messages

- Male exposure to lead is known to affect fertility, but it is unclear whether the levels currently prevalent in industry have this effect.

- We undertook a large, international, questionnaire based study focusing on Time To Pregnancy as a sensitive indicator of biological fertility, with blood lead levels as the principal measure of exposure.

- There was no clear pattern of association of Time To Pregnancy with short term lead exposure, with duration of lead exposure, or with cumulative exposure to lead.

were included, as in the case of miscarriage or other pregnancy loss recall may be less good for year of occurrence and covariates as well as for TTP. ${ }^{20}$ TTP values were eligible for inclusion if conception was reported to be not as a result of contraceptive failure, and if the target time (see below for definition) occurred after 1975 as insufficient information is available on lead exposure before then. Since TTP is a property of the couple, confounding factors were included for both male and female partners.

The exposed group consisted of those who were working in a lead exposed industry at the target time. There were two non-exposed populations: (a) external control group: men recruited in industries without lead exposure; (b) internal control group: men recruited through companies working with lead, but for whom the timing indicated that lead exposure could not have influenced their fertility when their youngest child was conceived.

Blood lead measurements were available for all the exposed groups as far back as the late 1970s, and the laboratories were subject to quality control programmes that would have minimised any spatial or temporal variation. Results are presented for three exposure models: (1) short term, reflecting recent exposure; (2) duration of exposure irrespective of its level; and (3) cumulative, a composite measure that integrates level and duration of exposure. For (1) and (3), exposure assessment was based on blood lead measurements when available, and imputed values when the measurements were missing but there was sufficient other information for an occupational hygienist to reliably allocate an exposure category $(\mathrm{n}=78)$. This imputation was based on information on the place where the man worked, together with information on the blood lead levels prevailing there at each time.

In each case, the timing of exposure has to be considered relative to the period of unprotected intercourse leading to that particular conception. The duration of spermatogenesis and spermiogenesis in the human is approximately three months. We assumed that the probability of an effect of lead exposure was equally distributed throughout this period, and the "target time" was therefore defined as six weeks before the beginning of unprotected intercourse (fig 1).

For the short term measure, the mean of up to four blood lead values was used: the closest value to the target time, if within 6 months; the next value after that, if within 12 months; and the two values before the closest value, if within 24 months. The use of up to four values was designed to produce a more stable estimate than would be possible with only one; the asymmetry of timing is designed to reflect the time during which lead might exert an effect. These short term mean values were analysed in terms of four exposure categories: $<20 \mu \mathrm{g} / \mathrm{dl}, 20-29 \mu \mathrm{g} / \mathrm{dl}, 30-39 \mu \mathrm{g} / \mathrm{dl}$, and $40+\mu \mathrm{g} / \mathrm{dl}$.

Duration was measured from the month/year of starting work in the industry to the target time, ignoring any gaps
Policy implications

- Current occupational lead exposures do not appear to affect male fertility.

- This observation is compatible with our previous finding of impaired spermatogenesis at the higher prevailing levels of exposure, which may not be sufficiently severe to interfere with fertilising capacity.

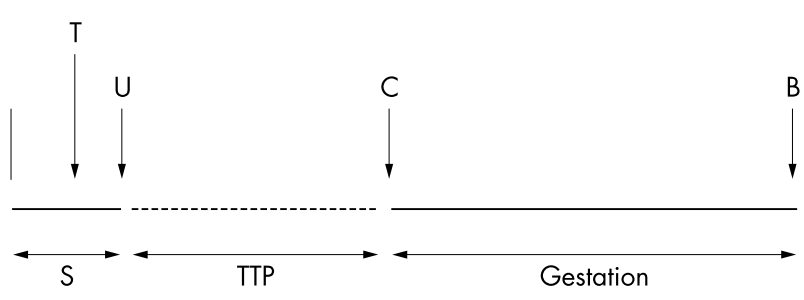

Figure 1 Calculation of target time for exposure assessment. T, target time; U, beginning of unprotected intercourse; C, conception; B, birth; S, duration of spermatogenesis and spermiogenesis (12 weeks); TTP, TTP interval (variable); Gestation, gestational length (default: 9 months).

(that is, taking them as being "exposed"). The cumulative measure was taken as the sum of the mean value in each year multiplied by the duration of exposure in that year, that is:

$$
\Sigma \mathrm{x}_{\mathrm{i}} \mathrm{y}_{\mathrm{i}}
$$

where $y_{i}=$ the length of exposure in year i (up to $1,=12$ months). The reason for taking means within a fixed time period (years in this instance) is to remove any possible effect of the density of measurements, as blood lead values may be determined once yearly, twice yearly, quarterly, or more often, with more frequent measurement typically being triggered by high values.

\section{Statistical analysis}

A Cox proportional hazards model with discrete ties was used. ${ }^{27}$ This generates a hazard ratio; higher values $(>1)$ indicate higher fertility. The results are presented separately with the external and internal control groups as baseline, both as unadjusted analyses and as multivariate analyses, adjusting for the effects of the following covariates: country, mother's age, mother's smoking, and whether it was the mother's first pregnancy. Father's age and smoking were considered for inclusion, but these variables were not associated with TTP, and were therefore not included in the models. The use of oral contraception was not included in the formal model, as the contraceptive pill tends to reduce fertility specifically in the early months after discontinuation of use, violating the assumption of proportional hazards. Therefore, as alternate analyses, separate models were estimated for men whose wives had or had not taken the pill immediately prior to commencing unprotected intercourse. In addition, the models were repeated after exclusion of all men with imputed blood lead data.

A number of precautions were taken to ensure unbiased analyses. First, the analysis was censored at 14 months (14 rather than 12 months because of digit preference), because values become sparse as TTP increases, making estimation of the upper tail of the TTP distribution unreliable. This also avoids problems due to the possible effects of fertility treatment. ${ }^{18}$ In addition, recall of the duration of relatively long periods of infertility is less accurate. ${ }^{20}$ Alternate analyses 
with censoring at 10 or 7 months were also carried out, to check whether the findings were sensitive to this.

Secondly, TTP values of 0 and 1 were grouped together, as it may be difficult for respondents to make a clear distinction when conception occurs very quickly; analyses were also repeated without this grouping of values. The following additional checks were carried out, to ensure that there were no unrecognised problems: (a) the proportion of pregnancies categorised as contraceptive failures was tabulated against exposure category, in case the discrimination of contraceptive failures from very quick conceptions happens to vary with lead category; (b) for the same reason, the basic analysis was repeated after deletion of all cases with a TTP of 0 or 1 , as recommended by Weinberg and colleagues. ${ }^{28}$

Finally, it was necessary to avoid truncation bias, ${ }^{29}$ due to the imposition of a calendar time cut off date (when data were collected), after which pregnancies are no longer included. This is a selection effect, affecting who is included in the analysis, and is completely separate from the issue of censoring. For example, a man who was interviewed in May 1997 and who had commenced unprotected intercourse with his wife in May 1996 would have a pregnancy only if the couple conceived within 12 months; the less fertile couples are thus excluded from the population at risk. This bias has the effect of artificially overestimating fertility in relation to births in the most recent category. As lead exposure has decreased during the relevant period, blood lead is highly correlated with calendar time, and truncation bias would be expected to create an artefactual tendency towards higher fertility in those with lower blood lead values. To ensure that the findings were not distorted by this bias, an alternate analysis was carried out excluding all those TTP values that related to a target time later than 1994. This cut off date was chosen because there are few instances of TTP values beyond 2-3 years, so that the bias becomes small at the population level. There was no equivalent bias at the beginning of the period studied, as inclusion was defined by the target time, not time of conception.

\section{RESULTS}

Table 1 lists the types of product covered by the study. Indications of the range of company sizes and duration of employment are also given. Mean values of blood lead were approximately $30 \mu \mathrm{g} / \mathrm{dl}$ in each of the participating countries. Although values up to $70 \mu \mathrm{g} / \mathrm{dl}$ were observed, such high values were rare, and levels of blood lead above $50 \mu \mathrm{g} / \mathrm{dl}$ were uncommon.

Response rates varied considerably: country specific rates varied from little over $50 \%$ to $85 \%$ or more. The attempt to distinguish non-responders from those known to be noneligible was not very successful. Where doubt existed, we have assumed non-responders to have been eligible, thus inflating the denominators. The response rates shown in table 1 may therefore be misleadingly low.

Out of 2293 questionnaires, 1899 men reported that they had fathered a child; 303 of these were reported to have followed a contraceptive failure, and of the remaining 1596, the TTP value was unknown $(n=139)$, or the target time was missing $(\mathrm{n}=2)$ or occurred prior to $1976(\mathrm{n}=351)$, leaving 1104 values for analysis (fig 2). Of these, 236 were from the external control group and 230 from the internal control group.

Table 2 tabulates respondents' characteristics in the different exposure groups (using the short term measure), including the two control groups. Men in the exposed groups tended to be older at the target time than those in the control groups, especially the internal control group, and this was true also of their wives. Some heterogeneity was noted between the exposure categories in the proportion of first pregnancies, smoking by either partner, and prior use of oral contraception, but no systematic pattern could be identified. Genitourinary disorders and treatment for infertility were infrequent, and did not vary systematically with exposure group.

Table 3 shows unadjusted TTP distributions by exposure category using the short term measure. The external control group and those with missing blood lead values were found to have a distribution that suggests considerably lower fertility than the other lead exposed workers including the internal control group. This is reinforced by a higher proportion of phases of infertility not leading to a pregnancy in the two former categories ( $8 \%$ and $9 \%$, respectively), compared with $3-5 \%$ in the lead exposed groups and internal control group. However, these same two categories also reported a high proportion of contraceptive failures, so that part of their apparent difference from the rest of the population may be behavioural rather than biological.

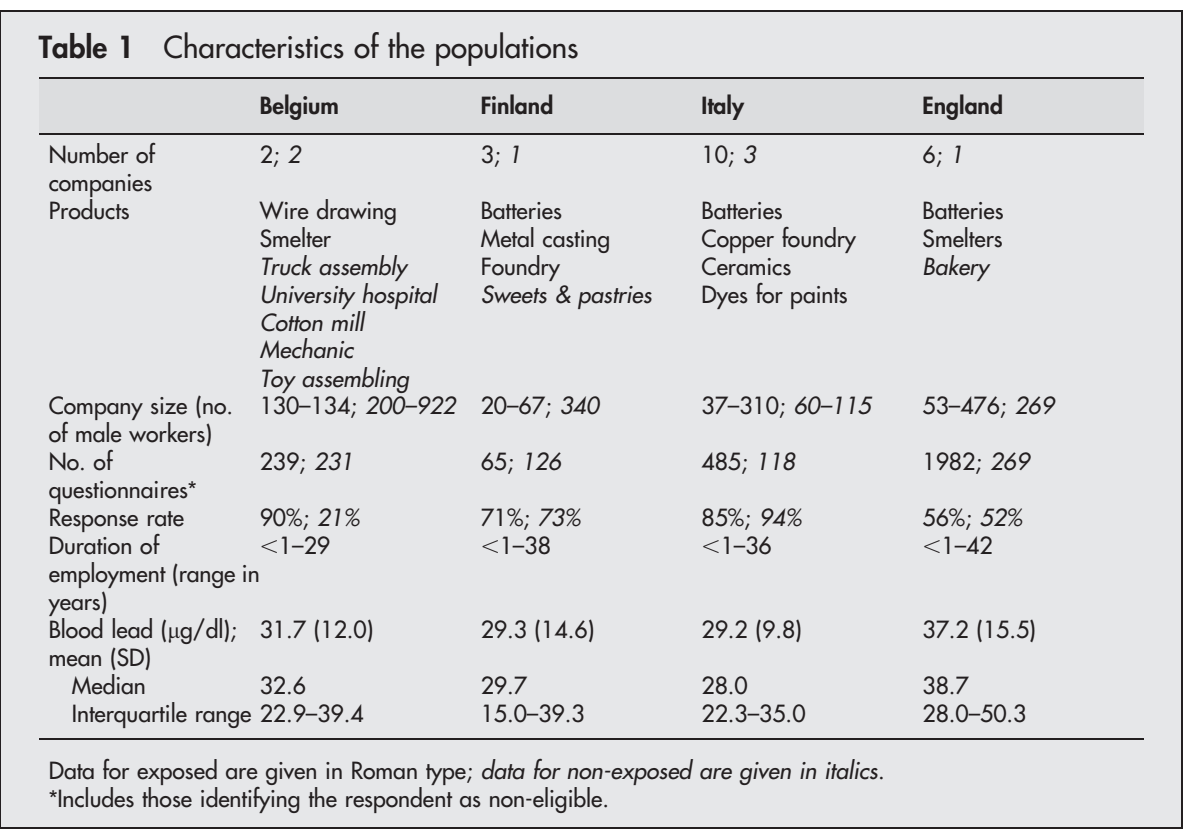




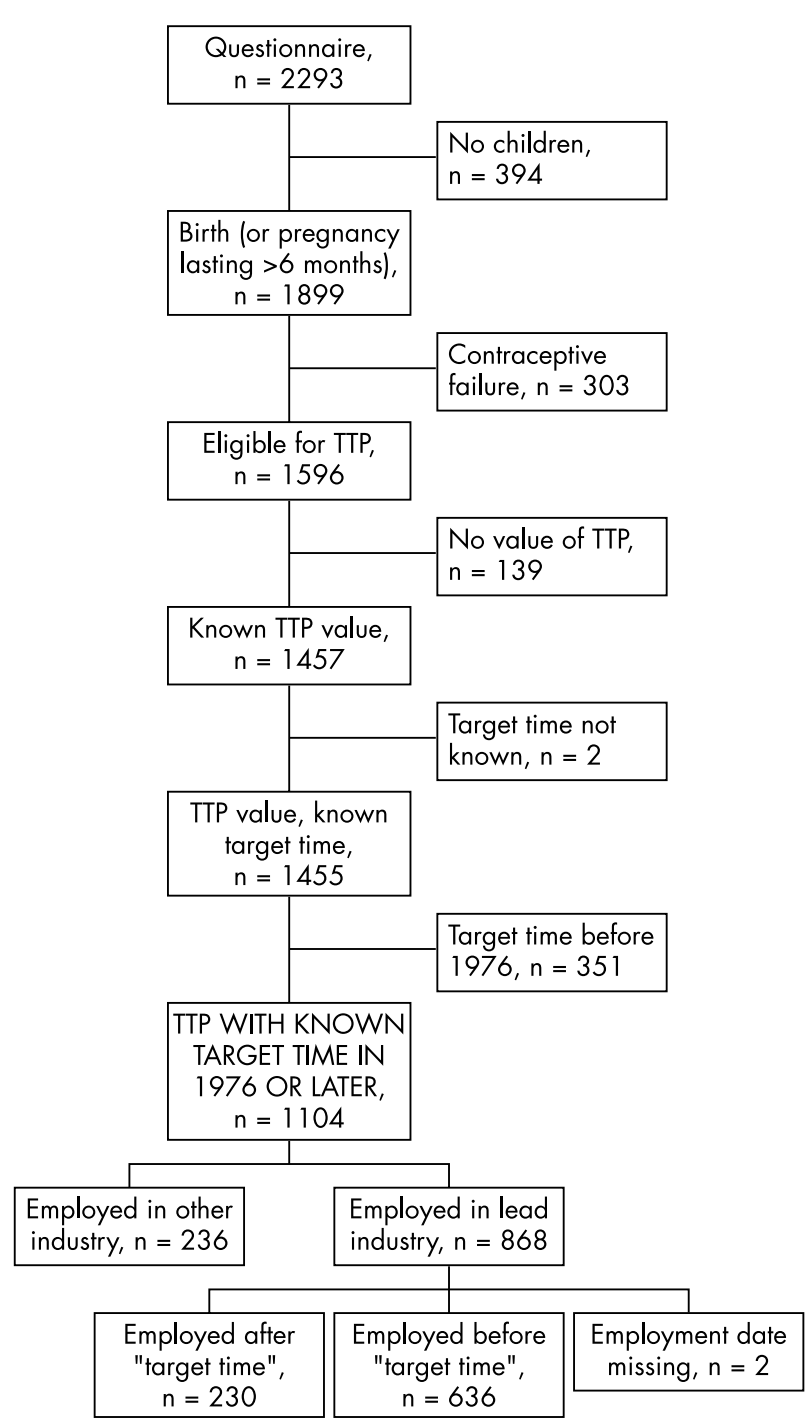

Figure 2 Flow chart showing the numbers of participants who were included or excluded.

The same results are given in the top half of table 4, in the form of a Cox proportional hazards model with discrete ties, adjusted for country (fertility was higher in Italy than in northern Europe). The second half of table 4 shows the same findings, adjusted also for maternal age, smoking, and first pregnancy. These confirm the apparently lower fertility of the external control group, which remains after adjustment. On the basis of the internal control group, no consistent or statistically significant decrease in fertility was observed in the exposed groups. The suspicion of a weak trend of decreasing fertility with increasing blood lead level within the exposed groups (table 3) disappeared when adjustment was made for country. The findings were closely similar when alternative measures of exposure were used, either the highest of the four values as previously defined, or the closest single value.

Tables 5 and 6 , in the same format as table 4, present the findings when the exposure measures used were respectively duration and cumulative lead exposure. Again, the external exposure group differed from all the lead workers. Within the latter group, men in the third category had lower fertility than those in the other three categories, but no clear pattern of association was seen between lead exposure and fertility.
The findings were unchanged when each of the alternate and sensitivity analyses was carried out. In addition, repeating the analysis after exclusion of all worksites with a response rate less than $75 \%$ gave virtually identical results.

\section{DISCUSSION}

This study found no evidence that low fertility is associated with the levels of occupational lead exposure that currently exist. We need to consider whether these negative findings could be due to misclassification of either exposure or outcome, to insufficient numbers or to some other type of bias.

Retrospective epidemiological studies of environmental or occupational exposures are frequently handicapped by inadequate exposure measurements. In this instance, we were able to make use of the blood lead values that have been a statutory requirement for all worksites with exposure to lead in the European Community since the late 1970s. Misclassification of exposure is therefore less likely to have been a problem in this study than in most others of the same design.

In the case of TTP, validation studies have shown that misclassification occurs, ${ }^{20-23}$ but that it is non-differential. Nevertheless, recall bias could have occurred in this population, and could possibly have influenced the results. However, it is difficult to explain why reporting of TTP should be distorted in any particular direction by the degree of lead exposure of the respondents. In addition, the expected associations of TTP with maternal age, smoking habit, and recent use of the contraceptive pill were found, which increases the confidence in our data.

The sample size was greater than 100 in most of the exposure groups. While a larger number would have been desirable, it seems unlikely that this would have altered the findings, but this cannot be ruled out.

It could be that response bias has influenced the results. A low response rate in many of the worksites, especially in England, was partly due to restrictions placed on the fieldwork; for example, men having to participate during their free time, and partly to the prevailing attitude that the researchers were looking for "volunteers". An additional factor in the Belgian external control group was study fatigue, as several other studies and enquiries had immediately preceded this one. The motivation whether or not to take part in a workplace survey on fertility is likely to be related to fertility experience and/or to exposure status (although such problems are more to be expected in a study of semen quality for example, in which the men have the opportunity to be tested). ${ }^{30}$ If men are more likely to have participated if they (a) have experienced fertility related problems, or (b) are aware of a possibly relevant occupational exposure, this would have the effect of biasing the results towards the null: those in the non-exposed groups would only be motivated to take part for reason (a), and would therefore be a selectively less fertile group for reasons unconnected with toxicological effects. The apparently low fertility of the external control group is compatible with this suggestion. On the other hand, the analysis that excluded worksites with low response rates $(<75 \%)$ gave the same results as the full analysis, suggesting that this interpretation is less likely to be important.

Values of TTP were available only for pregnancies that ended in births; although TTP values tend to be longer for miscarriages, ${ }^{31}$ their exclusion does not bias the results. ${ }^{12}$ In addition, only one pregnancy per couple was studied; this corresponds with the statistical method used, which assumes independence of events. Now that frailty models are available for survival analysis, it would be possible to increase the statistical power by including multiple pregnancies per 
Table 2 Summary of all variables for each exposure category (short term exposure model)

\begin{tabular}{|c|c|c|c|c|c|c|c|c|c|}
\hline Variable & Category & $\begin{array}{l}\text { External control } \\
(n=236)\end{array}$ & $\begin{array}{l}\text { Internal control } \\
(n=230)\end{array}$ & $\begin{array}{l}l<20 \mu \mathrm{g} / \mathrm{dl} \\
(\mathrm{n}=71)\end{array}$ & $\begin{array}{l}20-29 \mu \mathrm{g} / \mathrm{dl} \\
(\mathrm{n}=156)\end{array}$ & $\begin{array}{l}30-39 \mu \mathrm{g} / \mathrm{dl} \\
(\mathrm{n}=162)\end{array}$ & $\begin{array}{l}40+\mu \mathrm{g} / \mathrm{dl} \\
(\mathrm{n}=184)\end{array}$ & $\begin{array}{l}\text { Missing } \\
(n=65)\end{array}$ & $\begin{array}{l}\text { Total } \\
(n=1104)\end{array}$ \\
\hline \multirow[t]{4}{*}{ Country } & Belgium & 77 (33) & $14(7)$ & $17(24)$ & $19(12)$ & $19(11)$ & $15(8)$ & $9(14)$ & $170(15)$ \\
\hline & Finland & $71(30)$ & $4(2)$ & $6(8)$ & $4(3)$ & $5(3)$ & $4(2)$ & $9(14)$ & $103(9)$ \\
\hline & Italy & $36(15)$ & 76 (33) & 28 (39) & 89 (57) & 71 (44) & 24 (13) & $7(11)$ & 331 (30) \\
\hline & England & $52(22)$ & $136(59)$ & $20(28)$ & $44(28)$ & $67(41)$ & 141 (77) & $40(62)$ & $500(45)$ \\
\hline $\begin{array}{l}\text { Male age at } \\
\text { target time }\end{array}$ & Mean (SD) & $29(5)$ & $27(5)$ & $31(5)$ & $31(6)$ & $32(6)$ & $31(6)$ & $32(6)$ & $30(5)$ \\
\hline Male age group & $<30$ & $121(51)$ & $152(66)$ & $33(46)$ & $68(44)$ & $62(38)$ & $69(38)$ & $21(32)$ & $526(48)$ \\
\hline at target time & $30+$ & $114(48)$ & 78 (34) & $38(54)$ & $88(56)$ & $100(62)$ & $114(62)$ & $44(68)$ & $576(52)$ \\
\hline $\begin{array}{l}\text { Female age at } \\
\text { target time }\end{array}$ & Mean (SD) & $27(4)$ & $25(4)$ & $28(4)$ & $28(5)$ & $28(5)$ & $28(5)$ & $28(5)$ & $27(5)$ \\
\hline Female age group & $<30$ & $167(71)$ & $189(82)$ & $48(68)$ & $102(65)$ & $105(65)$ & $111(60)$ & $40(62)$ & $762(69)$ \\
\hline at target time & $30+$ & $28(29)$ & 39 (17) & $22(31)$ & $54(35)$ & 57 (35) & $70(38)$ & $22(34)$ & $332(30)$ \\
\hline \multirow[t]{2}{*}{ First pregnancy } & Yes & 81 (34) & 72 (31) & 23 (32) & 57 (37) & 33 (20) & 22 (12) & 19 (29) & 307 (28) \\
\hline & No & $155(66)$ & $158(69)$ & $48(68)$ & 99 (63) & $129(80)$ & $159(86)$ & 46 (71) & 794 (72) \\
\hline \multirow[t]{2}{*}{ Male smoking } & Yes & $106(45)$ & $120(52)$ & 19 (27) & 68 (44) & 89 (55) & $100(54)$ & 23 (35) & $525(48)$ \\
\hline & No & $129(55)$ & 109 (47) & 51 (72) & $88(56)$ & 73 (45) & $83(45)$ & $42(65)$ & 575 (52) \\
\hline \multirow[t]{2}{*}{ Female smoking } & Yes & $60(25)$ & 76 (33) & $15(21)$ & $35(22)$ & $44(27)$ & 49 (27) & 24 (37) & 303 (27) \\
\hline & No & 161 (68) & $151(66)$ & 55 (77) & 120 (77) & 117 (72) & 133 (72) & 41 (63) & 778 (70) \\
\hline \multirow{8}{*}{$\begin{array}{l}\text { Use of oral } \\
\text { contraceptive } \\
\text { Genitourinary } \\
\text { disorders } \\
\text { Infertility treatment } \\
\text { Year of occurrence } \\
\text { of target date }\end{array}$} & Yes & 100 (42) & 107 (47) & 34 (48) & 57 (37) & 62 (38) & 92 (50) & $28(43)$ & 480 (43) \\
\hline & No & 119 (50) & 123 (53) & 37 (52) & 98 (63) & 99 (61) & 91 (49) & 37 (57) & 604 (55) \\
\hline & Yes & $2(1)$ & $4(2)$ & $1(1)$ & $3(2)$ & $4(2)$ & $0(0)$ & $2(3)$ & $16(1)$ \\
\hline & Yes & $13(6)$ & $2(1)$ & $3(4)$ & $3(2)$ & 7 (4) & $6(3)$ & $1(2)$ & $35(3)$ \\
\hline & $76-80$ & 36 (15) & 48 (21) & $2(3)$ & 25 (16) & 29 (18) & 44 (24) & $33(51)$ & 217 (20) \\
\hline & $81-85$ & 42 (18) & $56(24)$ & 5 (7) & 29 (19) & $33(20)$ & $48(26)$ & $6(9)$ & $219(20)$ \\
\hline & $86-90$ & 55 (23) & 77 (33) & $18(25)$ & 38 (24) & 38 (23) & 43 (23) & 12 (18) & 281 (25) \\
\hline & $91+$ & $103(44)$ & 49 (21) & $46(65)$ & $64(41)$ & $62(38)$ & 49 (27) & 14 (22) & 387 (35) \\
\hline
\end{tabular}

All values are numbers of subjects (\% of lead group), unless otherwise stated. Missing values are not stated, but can readily be calculated from the totals for each exposure group. Except for genitourinary disorders and infertility treatment, they were approximately $5 \%$ of values or less.

couple, although this would require a longer and more complex questionnaire to obtain all the necessary information, including on covariates.

The results based on the external control group are more reliable, as comparison with the internal control group may be biased. For example, men who had been fertile before, but not after starting lead exposed work, would be represented in the internal control group despite unsuccessfully continuing unprotected intercourse after starting their new job. ${ }^{32}$

On the other hand, because lead exposure declined over time, longer values of TTP will have been associated with an earlier period during which exposures were higher. The resulting bias would have led to an overestimation of the association of lead exposure and biological fertility. ${ }^{33}$

Associations were observed between TTP and variables other than lead exposure, for example international differences, which have been observed previously. ${ }^{34}$ An apparent difference was also found between men recruited through the lead industry and those recruited as the external control group, unrelated to exposure status. A differential healthy worker effect is unlikely to be the explanation, as (a) reduced fertility would not be directly associated with work status, and (b) in this age group, the prevalence of chronic diseases that could affect both fertility and the ability to work would be expected to be rather low. This unexplained observation underlines the current lack of understanding of the determinants of heterogeneity in human biological fertility.

Other studies of TTP in men exposed to lead at similar exposure levels have had mixed results. Apostoli et al found decreased fertility among men with blood lead concentrations of at least $40 \mu \mathrm{g} / \mathrm{dl}$, but this was statistically significant only in a subgroup analysis restricted to subjects with just one child. ${ }^{3}$ Fertility was not at all reduced in men with blood lead concentrations in the range 30-40 $\mu \mathrm{g} / \mathrm{dl}$. Sallmén et al found lower fertility among all lead workers compared with non-exposed controls; within the lead exposed group, men with blood lead concentrations above $30 \mu \mathrm{g} / \mathrm{dl}$ had relatively low fertility, a finding that was almost statistically significant at the $5 \%$ level in the whole population, and highly significant when the analysis was confined to pregnancies that ended in a birth. ${ }^{12}$ The reasons for the discrepancies between the findings in the different studies are unclear at this stage.

In conclusion, no detectable effects on male fertility were found at the levels of lead exposure current in the types of western European worksite represented by this study population. In the parallel study previously mentioned, which also formed part of the Asclepios Project, we examined

Table 3 TTP distributions for each exposure category: short term exposure model

\begin{tabular}{|c|c|c|c|c|c|c|c|c|}
\hline Time period & $\begin{array}{l}\text { External control } \\
(n=236)\end{array}$ & $\begin{array}{l}\text { Internal control } \\
(n=230)\end{array}$ & $\begin{array}{l}<20 \mu \mathrm{g} / \mathrm{dl} \\
(\mathrm{n}=71)\end{array}$ & $\begin{array}{l}20-29 \mu \mathrm{g} / \mathrm{dl} \\
(\mathrm{n}=156)\end{array}$ & $\begin{array}{l}30-39 \mu \mathrm{g} / \mathrm{dl} \\
(\mathrm{n}=162)\end{array}$ & $\begin{array}{l}40+\mu \mathrm{g} / \mathrm{dl} \\
(\mathrm{n}=184)\end{array}$ & $\begin{array}{l}\text { Missing } \\
(n=65)\end{array}$ & $\begin{array}{l}\text { Total } \\
(n=1104)\end{array}$ \\
\hline 1 month & $66(28)$ & $111(48)$ & 35 (49) & $78(50)$ & $84(52)$ & $81(44)$ & 21 (32) & $476(43)$ \\
\hline 2 months & 43 (46) & $35(64)$ & 14 (69) & 32 (71) & 17 (62) & $25(58)$ & $12(51)$ & 178 (59) \\
\hline 3 months & $32(60)$ & $25(74)$ & $9(82)$ & $11(78)$ & $20(75)$ & 18 (67) & $8(63)$ & $123(70)$ \\
\hline 4-6 months & $43(78)$ & $27(86)$ & $6(90)$ & $12(85)$ & $14(83)$ & $30(84)$ & 9 (77) & 141 (83) \\
\hline 7-9 months & $10(82)$ & $8(90)$ & $1(92)$ & $5(89)$ & $5(87)$ & $6(87)$ & $2(80)$ & 37 (87) \\
\hline $10-12$ months & $19(90)$ & 9 (94) & $3(96)$ & $11(96)$ & 4 (89) & $7(91)$ & $4(86)$ & 57 (92) \\
\hline $13+$ months & $23(100)$ & $15(100)$ & $3(100)$ & $7(100)$ & $18(100)$ & $17(100)$ & $9(100)$ & $92(100)$ \\
\hline
\end{tabular}

The values given are the number becoming pregnant in that interval (in parentheses: cumulative percentages of those pregnant up to the end of the current interval), grouped for convenience. 
Table 4 Hazard ratios: short term exposure model

\begin{tabular}{|c|c|c|c|c|}
\hline \multirow{2}{*}{$\begin{array}{l}\text { Lead values } \\
\text { ( } \mu \mathrm{g} / \mathrm{dl})\end{array}$} & \multicolumn{2}{|c|}{ Relative to external control group } & \multicolumn{2}{|c|}{ Relative to internal control group } \\
\hline & Hazard ratio & $95 \% \mathrm{Cl}$ & Hazard ratio & $95 \% \mathrm{Cl}$ \\
\hline \multicolumn{5}{|c|}{ With adjustment only for country } \\
\hline$<20$ & 1.62 & $(1.22$ to 2.14$)$ & 1.14 & (0.86 to 1.51$)$ \\
\hline $20-29$ & 1.34 & (1.06 to 1.68$)$ & 0.94 & $(0.76$ to 1.17$)$ \\
\hline $30-39$ & 1.27 & $(1.01$ to 1.60$)$ & 0.89 & (0.72 to 1.11$)$ \\
\hline $40+$ & 1.35 & (1.07 to 1.69 ) & 0.95 & (0.77 to 1.16 ) \\
\hline \multicolumn{5}{|c|}{ With adjustment for country, mother's age, smoking, and primiparity } \\
\hline$<20$ & 1.56 & (1.17 to 2.07 ) & 1.12 & (0.84 to 1.49$)$ \\
\hline $20-29$ & 1.32 & (1.05 to 1.67 ) & 0.96 & (0.77 to 1.19$)$ \\
\hline $30-39$ & 1.22 & $(0.96$ to 1.54$)$ & 0.88 & $(0.70$ to 1.10$)$ \\
\hline $40+$ & 1.30 & (1.03 to 1.63 ) & 0.93 & $(0.76$ to 1.15$)$ \\
\hline
\end{tabular}

Table 5 Hazard ratios: duration of work in the industry

\begin{tabular}{|c|c|c|c|c|}
\hline \multirow{2}{*}{$\begin{array}{l}\text { Duration of exposure } \\
\text { (years) }\end{array}$} & \multicolumn{2}{|c|}{$\begin{array}{l}\text { Relative to external control group } \\
(n=236)\end{array}$} & \multicolumn{2}{|c|}{$\begin{array}{l}\text { Relative to internal control group } \\
(n=230)\end{array}$} \\
\hline & Hazard ratio & $95 \% \mathrm{Cl}$ & Hazard ratio & $95 \% \mathrm{Cl}$ \\
\hline \multicolumn{5}{|c|}{ With adjustment only for country } \\
\hline $0-4(n=223)$ & 1.26 & (1.01 to 1.55$)$ & 0.92 & $(0.75$ to 1.11$)$ \\
\hline $5-9(n=212)$ & 1.28 & (1.04 to 1.58 ) & 0.93 & $(0.77$ to 1.14$)$ \\
\hline $10-14(n=114)$ & 1.09 & $(0.85$ to 1.40$)$ & 0.79 & $(0.63$ to 1.01$)$ \\
\hline $15+(n=68)$ & 1.82 & (1.36 to 2.43 ) & 1.33 & (1.00 to 1.77$)$ \\
\hline \multicolumn{5}{|c|}{ With adjustment for country, mother's age, smoking, and primiparity } \\
\hline $0-4(n=223)$ & 1.24 & $(1.00$ to 1.54$)$ & 0.92 & $(0.76$ to 1.12$)$ \\
\hline $5-9(n=212)$ & 1.24 & (1.01 to 1.54 ) & 0.92 & $(0.75$ to 1.13$)$ \\
\hline $10-14(n=114)$ & 1.06 & $(0.82$ to 1.36$)$ & 0.78 & $(0.62$ to 1.01$)$ \\
\hline $15+(n=68)$ & 1.76 & (1.30 to 2.37 ) & 1.31 & $(0.96$ to 1.77$)$ \\
\hline
\end{tabular}

Table 6 Hazard ratios: cumulative lead exposure

\begin{tabular}{|c|c|c|c|c|}
\hline \multirow{2}{*}{$\begin{array}{l}\text { Cumulative values } \\
\text { ( } \mu \mathrm{g} / \mathrm{dl} \text { years) }\end{array}$} & \multicolumn{2}{|c|}{$\begin{array}{l}\text { Relative to external control group } \\
(n=236)\end{array}$} & \multicolumn{2}{|c|}{$\begin{array}{l}\text { Relative to internal control group } \\
(n=230)\end{array}$} \\
\hline & Hazard ratio & $95 \% \mathrm{Cl}$ & Hazard ratio & $95 \% \mathrm{Cl}$ \\
\hline \multicolumn{5}{|c|}{ With adjustment only for country } \\
\hline$<120(n=124)$ & $1.31^{\circ}$ & (1.02 to 1.68$)$ & 0.93 & (0.74 to 1.17$)$ \\
\hline $120-220(n=133)$ & 1.38 & (1.09 to 1.75 ) & 0.98 & (0.78 to 1.22$)$ \\
\hline $220-420(n=136)$ & 1.03 & $(0.81$ to 1.31$)$ & 0.73 & $(0.58$ to 0.91$)$ \\
\hline $420+(n=148)$ & 1.48 & (1.17 to 1.86$)$ & 1.05 & $(0.84$ to 1.30$)$ \\
\hline \multicolumn{5}{|c|}{ With adjustment for country, mother's age, smoking, and primiparity } \\
\hline$<120(n=124)$ & 1.28 & $(1.00$ to 1.65$)$ & 0.94 & (0.73 to 1.18$)$ \\
\hline $120-220(n=133)$ & 1.33 & (1.05 to 1.70 ) & 0.97 & (0.78 to 1.22 ) \\
\hline $220-420(n=136)$ & 0.97 & (0.76 to 1.24 ) & 0.71 & (0.56 to 0.89 ) \\
\hline $420+(n=148)$ & 1.43 & (1.13 to 1.81$)$ & 1.04 & (0.83 to 1.31 ) \\
\hline
\end{tabular}

semen quality in relation to current blood lead level. We found that sperm density was slightly reduced above a threshold that approximates to the highest exposure category in the present study. ${ }^{17}$ It would not be surprising that such a subtle change is not associated with an alteration in TTP. ${ }^{35}$

\section{ACKNOWLEDGEMENTS}

This research project would not have been possible without the participation of a large number of people who assisted in data collection at each of the worksites. It was funded by the Asclepios Project, an EU Concerted Action under the BIOMED programme, with an additional grant from the HSE (UK) for questionnaire development and translation and for statistical analysis. Data collection was funded by the Fund of Scientific Research
(Brussels), the Academy of Finland, and the HSE. The authors would like to thank Neela Shah and Paul Bassett for assistance with the statistical analyses.

\section{Authors' affiliations}

M Joffe, A Dale, Imperial College Faculty of Medicine, Department of Epidemiology \& Public Health, St Mary's Campus, Norfolk Place, London W2 1PG, UK

L Bisanti, Local Health Authority, Department of Epidemiology, Milano, Italy

P Apostoli, Università Studi di Brescia, Istituto Medicina del Lavoro, Brescia, Italy

P Kiss, M Vanhoorne, Ghent University, Occupational and

Environmental Health Section, Ghent, Belgium 
N Roeleveld, University of Nijmegen, Department of Epidemiology and Biostatistics, Nijmegen, Netherlands

M-L Lindbohm, M Sallmén, Finnish Institute of Occupational Health, Helsinki, Finland

J P Bonde, University of Aarhus, Department of Occupational Medicine, Aarhus, Denmark

Funding bodies: European Union, HSE (UK), the Fund of Scientific Research (Brussels), and the Academy of Finland

\section{REFERENCES}

1 Apostoli P, Kiss P, Porru S, et al. Male reproductive toxicity of lead in animals and humans. ASCLEPIOS Study Group. Occup Environ Med 1998;55:364-74.

2 Alexander $\mathrm{BH}$, Checkoway $\mathrm{H}$, van Netten $\mathrm{C}$, et al. Semen quality of men employed at a lead smelter. J Occup Med 1996;53:411-16.

3 Apostoli P, Bellini A, Porru S, et al. The effect of lead on male fertility: a time to pregnancy (TTP) study. Am J Ind Med 2000;38:310-15.

4 Assennato G, Paci C, Baser ME, et al. Sperm count suppression without endocrine dysfunction in lead-exposed men. Arch Environ Health 1986;41:387-90.

5 Bonde JPE, Kolstad H. Fertility of Danish battery workers exposed to lead. Int J Epidemiol 1997;26:1281-8.

6 Coste J, Mandereau L, Pessione F, et al. Lead-exposed workmen and fertility: a cohort study on 354 subjects. Eur J Epidemiol 1991;7:154-8.

7 Gennart J-P, Buchet J-P, Roels H, et al. Fertility of workers exposed to cadmium, lead, or manganese. Am J Epidemiol 1992;135:1208-19.

8 Lancranjan I, Popescu HI, Gavanescu O, et al. Reproductive ability of workmen occupationally exposed to lead. Arch Environ Health 1975:30:396-401.

9 Lerda D. Study of sperm characteristics in persons occupationally exposed to lead. Am J Ind Med 1992;22:567-71.

10 Lin S, Hwang S-A, Marshall EG, et al. Fertility rates among lead workers and professional drivers: a comparative study. Ann Epidemiol 1996:6:201-8.

11 Robins TG, Bornman MS, Ehrlich RI, et al. Semen quality and fertility of men employed in a South African lead acid battery plant. Am J Ind Med 1997;32:369-76.

12 Sallmén M, Lindbohm M-L, Anttila A, et al. Time to pregnancy among wives of men occupationally exposed to lead. Epidemiology 2000;11:141-7.

13 Sallmén $M$, Lindbohm $M-L$, Nurminen $M$. Paternal exposure to lead and infertility. Epidemiology 2000;1 1:148-52.

14 Selevan SG, Hornung R, Kissling GE, et al. Reproductive outcomes in wives of lead exposed workers. PB85-220879. Cincinnati, OH: US National Institute for Occupational Safety and Health, Department of Health and Human Services, 1984:1-42.

15 Sitarek K, Szymczak W, Berliñska B. Evaluation of reproductive disorders in men occupationally exposed to lead [in Polish, English abstract]. Med Pr 1998:49:137-45.
16 Viskum S, Rabjerg L, Jorgensen PJ, et al. Improvement in semen quality associated with decreasing occupational lead exposure. Am J Ind Med 1999;35:257-63

17 Bonde JP, Joffe M, Apostoli $P$, et al. Sperm count and chromatin structure in men exposed to inorganic lead: lowest adverse effect levels. Occup Environ Med 2002;59:234-42.

18 Joffe M, Asclepios. Time to Pregnancy: a measure of reproductive function in either sex. Occup Environ Med 1997;54:289-95.

19 Joffe M, Bisanti L, Apostoli P, et al. Time to pregnancy and occupational lead exposure: preliminary findings. Scand J Work Environ Health 1999;25(suppl 1):64-5.

20 Joffe M, Villard L, Li Z, et al. Long-term recall of time-to-pregnancy. Fertil Steril 1993:60:99-104.

21 Baird DD, Weinberg CR, Rowland AS. Reporting errors in time-to-pregnancy data collected with a short questionnaire: impact on power and estimate of fecundability ratios. Am J Epidemiol 1991;133:1282-90.

22 Zielhuis GA, Hulscher MEJL, Florack EIM. Validity and reliability of a questionnaire on fecundability. Int J Epidemiol 1992;21:1151-6.

23 Joffe M, Villard L, Li Z, et al. A time to pregnancy questionnaire designed for long term recall: validity in Oxford, England. J Epidemiol Community Health 1995:49:314-19.

24 Joffe $M$. Feasibility of studying subfertility using retrospective self reports. $J$ Epidemiol Community Health 1989;43:268-74.

25 Joffe M, Li Z. Male and female factors in fertility. Am J Epidemiol 1994:140:921-9.

26 Joffe M. Time trends in biological fertility in Britain. Lancet 2000;355:1961-5.

27 Cox DR, Oakes D. Chapter 7. Analysis of survival data. New York: Chapman and Hall, 1984.

28 Weinberg CR, Baird DD, Wilcox AJ. Sources of bias in studies of time to pregnancy. Stat Med 1994;13:671-81.

29 Scheike TH, Jensen TK. A discrete survival model with random effects: an application to time to pregnancy. Biometrics 1997:53:349-60.

30 Larsen SB, Abell A, Bonde JP. Selection bias in occupational sperm studies. Am J Epidemiol 1998;147:681-5.

31 Joffe M, Li Z. Association of time to pregnancy and the outcome of pregnancy. Fertil Steril 1994:62:71-5.

32 Sallmén M. Fertility among workers exposed to solvents or lead. PhD dissertation. People and Work, Research Reports 37. Finnish Institute of Occupational Health, Helsinki, 2000.

33 Weinberg CR, Baird DD, Wilcox AJ. Sources of bias in studies of time to pregnancy. Stat Med 1994;13:671-81.

34 Juul S, Karmaus W, Olsen J. Regional differences in waiting time to pregnancy: pregnancy-based surveys from Denmark, France, Germany, Italy and Sweden. The European Infertility and Subfecundity Study Group. Hum Reprod 1999;14:1250-4.

35 Bonde JP, Hjollund NH, Kolstad HA, et al. Environmental semen studies - is infertility increased by a decline in sperm count? Scand J Work Environ Health 1999;25(suppl 1):12-16. 